correct, the leaves of the electroscope in connection with this plate should show an increased divergence, but the reverse effect was observed. The leaves partially cullapsed. In all experiments that I have made by inserting dielectrics between a charged body and an electroscope, less electric action has been the result. If while the charged ball be near the electroscope the plate of it be touched with the finger, the leaves collapse, and on removing the finger and then the charged ball they again diverge.

Now let a dielectric be placed between the ball and the electroscope, touch the latter, and remove the finger and ball as before, and much greater divergence will be produced. In both cases the electroscope is charged by induction. Without putting the electroscope to earth, I fail to see theoretically why any greater divergence should occur. I suppose someone must have made the experiment as quoted, but if a greater effect was produced it must have been caused by the substance used for a dielectric being charged itself. I have found very great difficulty in preventing plates of ebonite, paraffin, sulphur, \&c., becoming electrified when placed near a charged body.

I should like to know if anyone has experimented in this direction, because either the text-books or myself must be wrong. In Guthrie's book (p. IOI) there is a statement similar to Ganot's.

W. A. RUDGE.

\section{Who discovered the Teeth in Ornithorhynchus?}

ON returning from Central Arizona, where I have been engaged in biological explorations, I find upon my desk an important paper entitled "On the Dentition of Ornithorhynchus," by my friend $\mathrm{Mr}$. Oldfield Thomas, Curator of Mammals in the British Museum (see Proc. Royal Soc., vol. xlvi , 1889, 126-r 3 r, pl. 2).

The opening sentence of this paper is as follows: "At the meeting of the gth of February, I888, Mr. E. B. Poulton communicated to this Society the first discovery of the presence of teeth in Ornithor hynchus, a discovery which naturally awakened extreme interest throughout the scientific world." A few lines further on Mr. Thomas continues: "The grand fact of the presence of teeth in Monotremes, and their mammalian nature, are discoveries on which Mr. Poulton may well be congratulated."

From the above I infer that considerable stir has been made by the assumed new "discovery" that the young Ornithorhynchus has teeth.

If my British colleagues will turn to the masterly work of their illustrious countryman, Sir Everard Home, they will find in the second volume of his "I ectures on Comparative Anatomy" (published in 1814), no less than three beautifully engraved plates, containing eight figures, of the skull and mouth parts of Ornithorhynchus. Four of these figures show the teeth - $t$ wo on each side of each jaw. Tle explanation accompanying Fig. I, Tab. lix., is as follows: "A view of the upper jaw and palate, to show that there are two grinding teeth on each side." Fig. 2 is "a similar view of the under jaw."

Washington, D.C., October 12 .

C. Hart MERriam.

\section{ON THE HARDENING AND TEMPERING OF STEEL.}

I.

THE fact that the British Association meets this year at Newcastle no doubt suggested to the Council that it would be well to provide, for the first time since 1848 , a lecture on a metallurgical subject. In that year a discourse was delivered at Swansea by Dr. Percy, one of the most learned metallurgists of our time, who has recently passed away, after having almost created an English literature of metallurgy by the publication of his well-known treatises, without which it would have been comparatively barren. It was to him that the country turned in 1851 when it became evident that our metallurgists must receive scientific training.

I know that it has occurred to many that the various problems involved in the "hardening and tempering of steel" must be incapable of adequate treatment in the brief limits of a discourse like this, while others will think

"A Lecture delivered on "Septemher 13, by Prof. W. C. Roberts-Austen, F.R.S., before the memlers of the British Associaticn. that the details of the process, which is practised daily in thousands of workshops, are so well known that it is unnecessary to devote a lecture to the subject. It seemed to me that the entire question was the most important I could choose, partly because it will enable a large number of people who are engaged in industrial work, and who are not expected to think about it in a scientific way, to know how such facts as we shall bave to examine have been dealt with by scientific investigators; while those of our members who do not consider that their thoughts or work are scientific in its strictest sense, may perhaps be interested to see how absolutely industrial progress depends upon the advancement of science. This consideration has led me to deal with the subject in a somewhat comprehensive way. The treatment of iron in its several forms is the thing that we as a nation do well. If it be true that national virtues are manifestly expressed in the industrial art of a people, we may recall the sentence in Mr. Ruskin's "Crown of Wild Olive" in which he says, "You have at present in England only one art of any consequence-that is, iron-working," adding, with reference to the manufacture of armour-plate, "Do you think, on those iron plates your courage and endurance are not written for ever, not merely with an iron pen, but on iron parchment?" It may be well, therefore, to consider what properties iron possesses which entitle its application to industrial use to specially represent the skill and patience of the nation.

In 1863, Lord Armstrong, in his address as President of this Association, expressed the hope "that when the time again comes round to receive the British Association in this town, its members will find the interval to have been as fruitful as the corresponding period," since the previous meeting in 1838 , "on which they were then looking back." "In one way at least this hope has been realized, for the efforts of the last twenty years have resulted in the development of an "age of steel." When the Association last met here, steel was still an expensive material, although Bessemer had, seven years before, communicated his great invention to the world through the British Association at its Cheltenham meeting. The great future in store for Siemens's regenerative furnace, which plays so important a part in the manufacture of steel, was confidently predicted in his Presidential address by Lord Armstrong, than whom no one was better able to judge, for no one had done more to develop the use of steel of all kinds.

Steel, we shall see, is modified iron. The name iron is in fact a comprehensive one, for the mechanical behaviour of the metal is so singularly changed by influences acting from within and without its mass, as to lead many to think, with Paracelsus, that iron and steel must be two distinct metals, their properties being so different. Pure iron may be prepared in a form as pliable and soft as copper, steel can readily be made sufficiently hard to cut glass, and notwithstanding this extraordinary variance in the physical properties of iron and certain kinds of steel, the chemical difference between them is comparatively very small, and would hardly secure attention if it were not for the importance of the results to which it gives rise. We have to consider the nature of the transformations which iron can sustain, and to see how it differs from steel, of which an old writer has said, "Its most useful and advantageous property is that of becoming extremely hard when ignited and plunged into cold water, the hardness produced being greater in proportion as the steel is hotter and the water colder. The colours which appear on the surface of steel slowly heated direct the artist in tempering or reducing the hardness of steel to any determinate standard." There is still so much confusion between the words "temfer," "tempering," and "hardening," in the writings of even very eminent authorities, that it is well

$r$ "The First. Principles of Chemistry," ky W. Nicholson, p. $3: 2$ iLendon, x790). 
to keep these old definitions carefully in mind. I shall e:mploy the word tempering in the sense of softening, as Falstaff uses it when he says of Shallow :-

"I have him already tempering between my finger and my thumb, and shortly will I seal with him." 1

softening, that is, as brittle wax does by the application of gentle heat. Hardening, then, is the result of rapidly cooling a strongly heated mass of steel. Tempering consists in re-heating the hardened steel to a temperature far short of that to which it was raised before hardening : this heating may or may not be followed by rapid cooling. Annealing consists in heating the mass to a temperature higher than that used for tempering, and allowing it to cool slowly.

First, let the prominent facts be demonstrated experimentally.

[Three sword-blades of identical quality, made by an eminent sword-smith, Mr. Wilkinson, were taken. It was shown by bending one that it was soft; this was heated to redness and plunged into cold water, when it became so hard that it broke on the attempt to bend it Another was bent into a bow, the arc of which was four inches shorter than the sword itself, a common test for "temper," and it sprang back to a straight line when the bending force was removed; this had been tempered. A third, which had been softened by being cooled slowly, bent easily and remained distorted.

The metal has been singularly altered in its properties by comparatively simple treatment, and all these changes it must be remembered have been produced in a solid metal to which nothing has been added, and from which nothing material has been taken. The theory of this operation which I have just conducted has been laboriously built up, and its consideration introduces many questions of great interest both in the history of science, and in our knowledge of molecular physics. First as regards the history of the subject. The knowledge that steel might be hardened must have come to us from remote antiquity. Copper hardened with tin was its only predecessor, and it continued to be used very long after it was known that steel might be hardened. It would, moreover, appear that a desire to appreciate the difficulties of a people to whom cutting instruments of hard steel were unknown, seems to have induced experimenters in quite recent times to fashion implements of bronze, and a trustworthy authority tells us that "Sir Francis Chantry formed an alloy containing about I6 parts of copper, $2 \frac{1}{2}$ of zinc, and $2 \frac{1}{2}$ of tin, of which he had a razor made, and I believe even shaved with it." The Greek alchemical manuscripts which have been so carefully examined by $M$. Berthelot give various receipts from which it is evident that in the early days the nature of the quenching fluid was considered to be all-important. There were certain rivers the waters of which were supposed to be specially efficacious. Pliny, who says that the difference between waters of various rivers can be recognized by workers in steel, also knew that oil might be used with advantage for hardening certain varieties of the metal. It is sad to think how many of the old receipts for hardening and tempering have been lost. What would we not give, for instance, for the records of the Gallic prototype of our Iron and Steel Institute, the "Collegium Fabrorum Ferrariorum," 3 a guild with similar aims, formed in the time of the Roman Republic, for the advancement of knowledge, for the good of the State, and not for that of its individual members? The belief, how ever, in the efficacy of curious nostrums and solutions for hardening steel could hardly have been firmer at any period than in the sixteenth century of our era Shake-

I King Henry IV, Part II., Act iv., Scene 3.

2 "Engines of War," by H. Wilkinson, p. $194(\mathrm{r} 8+\mathrm{r})$.

3 “La Ferronnerie," par F. Liger, t. ii. p. 147 (Paris, 1875). speare suggests that $C$ thello's sword " of Spain " had been hardened in a cold stream for he says it had

"the ice brook's temper";

but cold water was far too simple a material for many a sixteenth century artificer to employ, as is shown by the quaint recipes contained in one of the earliest books of trade secrets, which, by its title, showed the existence of the belief that the "right use of alchemy" was to bring chemical knowledge to bear upon industry. The earliest edition was published in $I 53^{I}, 1$ and the first English translation ${ }^{2}$ in 1583 , from which the following extracts may be of interest. "Take snayles, and first drawne water of a red die of which water being taken in the two firste moneths of haruest when it raynes," boil it with the snails, "then heate your iron red hote and quench it therein and it shall be hard as steele." "Ye may do the like with the blood of a man of xxx yeres of age, and of sanguine complexion, being of a merry nature and pleasaunt . . . distilled in the middst of May." This may seem trivial enough, but the belief in the efficacy of such solutions survived into the present century, for I find in a work published in 1810 that the artist is prettily directed " ${ }^{3}$ " to take the root of blue lilies, infuse it in wine and quench the steel in it," and the steel will be hard; on the other hand, he is told that if he "takes the juice or water of common beans and quenches iron or steel in it, it will be soft as lead." I am at a loss to explain the confusion which has arisen from this source. As must always be the case when the practice of an art is purely empirical, such procedure was often fantastic, but it is by no means obsolete, for probably at the present day there is hardly a workshop in which some artificer could not be found with a claim to possess a quaint nostrum for hardening steel. Even the use of absurdly compounded baths, to which I have referred, was supported by theoretical views. Otto Tachen, ${ }^{4}$ for instance, writing of steel in about the year I666, says that steel when it is "quenched in water acquires strength because the light alcaly in the water is a true comforter of the light acid in the iron, and cutlers do strengthen it with the alcaly of animals," hence the use of snails. Again, Lemery ${ }^{5}$ explains in much the same way the production of steel by heating iron in the presence of horns of animals.

I have dwelt so long on these points in order to bring out clearly the fact that the early workers attached great importance to the nature of the fluid in which hot steel was quenched, and they were right, though their theories may have been wrong. The degree of rapidity with which heat is abstracted from the steel during the operation of hardening is as important at the present day as it ever was. Roughly speaking, if steel has to be made glass-hard, ice-cold water, brine, or mercury, is used ; if it has only to be made slightly hard, hot water or oil may be employed; while, as Thomas Gill ${ }^{6}$ suggested in 1818, both "hardening" and "tempering" may be united in a single operation by plunging the hot metal in a bath of molten lead or other suitable metal, which will of course abstract the heat more slowly.

We must now trace the development of theories relating to the internal constitution of steel. The advent of the phlogistic school with the teaching of Becher and Stahl led to the view that iron gained phlogiston during its conversion into steel. By phlogiston we know that the early chemists really meant energy, but to them phlogiston was represented to be a kind of soul possessed by all metals,

I "Rechter Gebrauch d. Alchimei," r53r. There were many English edition:

2 "A profitable boke declaring dyuers approoused remedies," \&c. (London,

1583). See Prof. Ferguson's learned paper "On some Early 'Treatises on $1583)$. See Prof. Ferguson's learned paper "On some Early
Technological Chemistry," Phil. Suc., Glasgow, January 1886.

3 "The Laboratory or Schcol of Arts," 6th edition, 1799, p. 228. There is a later edition of 18 ro.

4 " His Key to the Ancient Hippocratical Learning," p. 68 (London, $1690)$.

5 "A Course of Chemistry," and edition, 1686, p. I3r.

6 Thom son's Annals of P'hilo ophy, xii., 1818, p. $5^{8}$. 
which they could lose by burning and regain by the pro. cess they called "revivification." "Hardness [in metals] is caused by the jeiunenese of the spirit and their imparity with the tangible parts," said Francis Bacon $;^{1}$ while, according to Stahl, ${ }^{2}$ steel was merely iron possessing, in virtue of its phlogiston, the characteristics of a metal in a higher degree; and this view prevails in the writings of Henckel, Newmann, Cramer, Gellert, Rinman, and Macquer. This opinion survived with wonderful persistence, but it did not influence the teaching of Réaumur, ${ }^{3}$ who, in 1722 , was, so far as I know, the first to suggest a physical theory which has been in any way justified by modern research. He assumed that when steel was heated "sulphurs and salts" were driven out from the molecules, which he represents diagrammatically, into the interstitial space between them. The quenching of the steel and its sudden cooling prevented the sulphurs and salts from returning into the molecules, which were thus firmly cemented by the matter between them, and hard rigid steel was the result. In tempering, the sulphurs and salts partially returned into the molecules, and the metal became proportionately soft. I have elsewhere shown ${ }^{4}$ that he used the Torricellian vacuum to demonstrate that the hardening of steel is not accompanied by the evolution of gas, and he concluded that "since the hardening of steel is neither due to the intervention of a new substance nor to the expulsion of air, it only remains to seek its cause in the changes occurring in its structure." Notwithstanding this, the phlogistic school were not daunted, and this brings me to the work of Torbern Bergman, the great Professor at the University of Upsala, who in $178 \mathrm{I}$ showed ${ }^{5}$ that steel mainly differs from iron by containing about ${ }^{2} 0$ per cent. of plumbago, while iron does not. Read in connection with modern research, his work seems wonderfully advanced. He was so forcibly impressed by the fact that the great difference in the mechanical properties of different specimens of iron is due to the presence of small quantities of impurity, and that the properties of iron do not vary, as he says, unless by chance the iron has gathered foreign matter, "nisi forte peregrinum paullo uberius inhcerat metallum." We find, even, the dawn of the view that under the influence of small quantities of foreign matter iron is, as he calls it, polymorphous, and plays the part of many metals. "Adeo ut jure dici queat, polymorphum ferrum plurium simul metallorum vices sustinere." 6 Unfortunately he confounded the plumbago or carbon he had isolated with phlogiston, as did Rinman in 1782 , which was strange, because, in 1774 , the latter physicist had shown that a drop of nitric acid simply whitens wrought iron, but leaves a black stain on steel. Bergman tenaciously held to the phlogistic theory in relation to steel; it was inevitable that he should. The true nature of oxidation had been explained; no wonder that the defenders of the phlogistic theory should seek to support their case by appealing to the subtle and obscure changes produced in iron by such apparently slight causes. Bergman's view was, however, combated by Vandermonde, Berthollet, and Monge, ${ }^{7}$ who showed in a report communicated to the Académie des Sciences, in 1786 , that the difference between the main varieties of iron is determined by variation in the amount of carbon, and further that steel must contain a certain quantity of carbon in order that it might possess definite qualities. Bergman died in 1784 , and the report to which I have referred is full of respect for "this

I "Sylva Sylvarum," and edition, I628, p. 215

"Fundamenta Chemiæ," Part 3, p. 45i, quoted by Guyton de Morveau in the article "Acier," "Encyc. Méthodique," p. 421 (Paris, 1786 ).

3 "L'art de convertir le fer forgé en acier," p. 321 et seq. (Paris, 1722).

4 Proc. Inst. Mech. Ergineers, October r88r, p. 706.

5 "Opuscula Physica et Chemica," vol. iii. "De Analysi Ferri" (Upsala, 1783). A dissertation delivered June 9, $178 x$.

6 "De Analysi Ferri," p. 4.

7 "Histoire de l'Acadénie R pyale des Sciences," 786 (printed 1788), p. grand chemist," as its authors call him, "whom science had lost too soon."

Kirwan's essay on phlogiston, ${ }^{1}$ in which Bergman's views were defended, elicited a reply from Lavoisier himself, and brought down the French school in strength to contest almost the last position occupied by the believers in phlogiston. ${ }^{2}$

An entire lecture might be profitably devoted to Bergman's work. His was almost the first calorimetric research, and is specially interesting when taken in connection with the calorimetric investigations of Lavoisier and Laplace in 1780 , and it is impossible to read it without feeling that in paying the just tribute to Lavoisier's genius Bergman has been overlooked. He desired to ascertain whether pure iron, steel, and cast iron contain the same amount of heat. He therefore attacked the materials with a solvent, and noted the heat evolved. He says the solvent breaks up the assemblage of the aggregation of molecules and forms other unions. If the new body demands more heat than the body which has been disunited, then the thermometer will fall. If, on the other hand, the degree of heat required is less, the environment will be heated, which will result in the rise of the thermometer. The modern development is that, when a chemical compound is formed, heat is evolved and energy is lost, but if one substance, say a metal, simply dissolves another, the solution is attended with absorption of heat, and the product when attacked by a suitable solvent should evolve practically the same amount of heat, but certainly not less than would be evolved by the individual metals present in solution. ${ }^{3}$ This is specially interesting from its relation to the calorimetric work of Lavoisier and Laplace in 1780 and of Lavoisier in 1782 , which led the latter to explain the nature of oxidation, and to show that a metal could be as truly "calcined" or oxidized by the action of a solution as by the action of air at an elevated temperature. Now that the importance of thermochemistry is beginning to be recognized in relation to industrial chemistry and metallurgy, it is to be hoped that Bergman's merits will be more fully considered. We are, however, mainly concerned with the fact that he taught us that the difference between iron and steel consists in the $i^{2} \overline{0}$ to $I_{2} \frac{1}{2}$ per cent. of carbon which steel contains. It was only natural that Black, writing in 1796 , should have attributed the hardening of steel to the "extrication of latent heat"; "the abatement of the hardness by the temper" being due, he says, "to the restoration of a part of that heat." 4 Black failed to see that the work of Bergman had entirely changed the situation. The next step was made in France. It was considered necessary to establish the fact that carbon is really the element which gives steel iis characteristic properties, and with this object in view, Clouet, ${ }^{5}$ in 1798 , melted a little crucible of iron, weighing 57.8 grammes, containing a diamond, weighing 0.907 gramme, and obtained a fused mass of steel (Fig. I).

His experiment was repeated by many observers, but the results were open to doubt from the fact that furnace gases could always obtain access to the iron, and might, as well as the diamond, have yielded carbon to the metal.

r R. Kirwan, "Essay on Phlogiston and the Constitution of Acids," p. ${ }_{2} 34\left(17^{8} 7\right)$.

notes de M M. de Mlogistique," traduit de l'Anglois de M. Kirwan, avec des Fourcroy (Paris, I788).

3 See French translation of Bergman's work (Paris, I783), p. 72. The question is, however, so impurtant that I append the original Latin text:"Menstruo laxatur compages molecularum, et nova furmantur crnubia, quæ, si majorem, quam diruta, figunt materiæ caloris quantitatem, in vicini calor ad restituendum aquilibrium dıminuatur oportet, et thermometri hydrargyrum ideo subsidet: si minorem, differentia liberatur et viciniam calefacit, unde etiam adscendit thermometri liquor; si denique nova connubia eamdem precise quantitatem postularit, ouod raro acc dit, nulla in thermo( metro videbilur variatio." - Torberni Bergman, ".

Chemica," vol. ini. p. 58, $5_{78}$ ("De Analysi Ferri ")

4 "Lectures on the Elements of Chemistry," vol. ii p. 505 (1803)

Morveau, Ann. de Chim., xxxi. 1799, p. 328 . 
The carbon might have been presented to the iron in the form of a gas capable of yielding carbon, and this element would as surely have found its way into the steel.

Margueritte ${ }^{1}$ for instance, in $\mathbf{I} 865$, repeated Clouet's experiment, and showed that, although carburization can be effected by simple contact of iron and carbon, it is nevertheless true that in the ordinary process of cementation the gas carbonic oxide plays an important part, which had until then been overlooked. The discovery by Graham, ${ }^{2}$ in 1866 , of the occlusion of carbonic oxide by

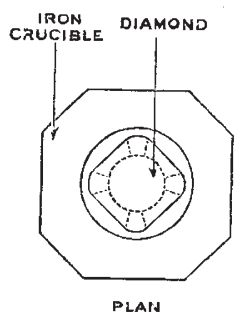

FIG, I.-Plan of ircn crucible and diamcnd from the drawing in Guyton de Mcrveau's paper. In the original, the diamcnd and the crucible are drawn, in plan, separately.

iron, gave additional support to this theory. I am glad to remember that he intrusted the experiments to me.

The question, however, of the direct carburization of iron by the diamond has never been doubted since 1815 , when a working cutler, Mr. Pepys, ${ }^{3}$ heated iron wire and diamond dust together and obtained steel, the heat being afforded by a powerful electric battery. I am anxious to make this absorption of carbon in the diamond form clear by this diagram (Fig. 2).

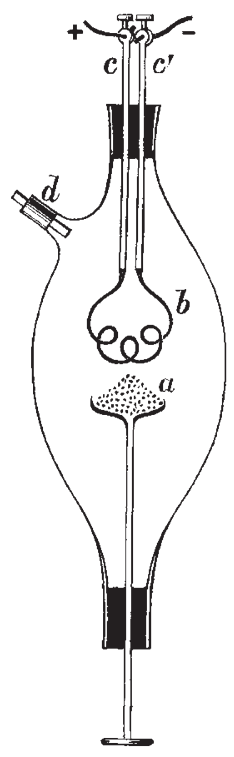

FIG. 2 represents a glass vessel which may either be rendered vacuous or may be filled with an atmosphere of gas through the tube $d$. An iron wire, $b$, placed between the terminals of a battery, $c, c^{\prime}$, is heated to redness. and remains glowing until it is touched by pure diamond dust, which is and fuses.

Do not think for a moment that the steel owes its hardness to the passage of diamond into the iron, as diamond. I have repeated Margueritte's form of Clouet's experiment, using, however, a vacuum instead of an atmo-

\footnotetext{
I "Sur l'aciération," Ann. Chim. et Phys., t. vi. [4], I 865 .$$
2 \text { Phil. Trans. Roy. Soc., 1866, pp. 399-439. }
$$

3 Ibid., 18 I5, p. 37 x.
}

sphere of gas, and employing the form of apparatus shown in this diagram (Fig. 3). [The carburized iron which was the result of the experiment was thrown upon the screen.] The diamond by union with iron has passed partially at least to the other form of carbon, graphite, while treatment with a solyent which removes the iron shows that carbon has entered into intimate association with the iron, a fact which leads us to the next step in the study of the relations between carbon and iron.

Hempel ${ }^{1}$ has shown that, in an atmosphere of nitrogen, iron appears to assimilate the diamond form of carbon more readily than either the graphitic or the amorphous

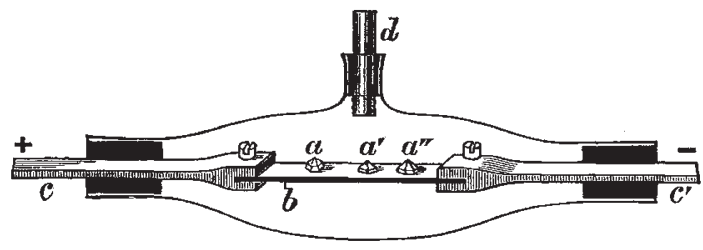

FIG. 3 represents an arrangement for heating the diamond and iron in vacuo. A strip of pure iron, $b$, is placed betw een two terminals, $c, c^{\prime}$, which are connected with a dynamo. The vessel (of glass) is rendered vacuct by connecting the tube with a Sprengelpump. by the dynamo, and maintained glowing until all ocluded gas is expelled from the iron, which is then allowed to cool in vaci!o. Small pure diamonds, $a, \alpha^{\prime}, \alpha^{\prime \prime}$, are then placed on the strip of iron through the orifice into which the tube $d$ fits. The vessel is rendered vacuous, and when the iron is again heated in ccntact with the diamcnds it fuses and combines with them.

forms, but directly carbon is associated with molten iron it behaves like the protean element it is, and the stafe which this carbon assumes is influenced by the rate of cooling of the molten mass, or even by the thermal treatment to which the solidified mass is subjected. Let me repeat, all are familiar with carbon in the distinct forms of diamond, graphite, and soot: all are alike carbon. It need not be considered strange, then, that carbon should be capable of being present in intimate association with iron, but in very varied forms.

Now the mode of existence of carbon in soft annealed steel is very different from that in which it occurs in hard steel. I believe that Karsten was the first to isolate, in 1827 , from soft steel a true compound of iron and carbon. Berthier ${ }^{2}$ also separated from soft steel a carbide of iron, to which he assigned the formula $\mathrm{FeC}$; but to attempt to trace the history of the work in this direction would demand an entire lecture. I will only add that within the last few years Sir F. Abel has given much experimental evidence in favour of the existence in soft cold rolled steel of a carbide, $\mathrm{Fe}_{3} \mathrm{C}$, which he isolated by the slow solvent action of a chromic acid solution. His work has been generally accepted as conclusive, and has been the startingpoint of much that has followed.

It will occur to you that the microscope should reveal wide differences between the structure of various kinds of iron and steel, and I am happy to be able to give you enlarged diagrams made from the drawings of Mr. Sorby, the eminent microscopist, which illustrated his very delicate investigations into the structure of steel. ${ }^{3}$

The point I am mainly concerned with is the existence of a substance which Sorby called the "pearly constituent" in soft steel. This pearly constituent is closely related to the carbide of iron, $\mathrm{Fe}_{3} \mathrm{C}$ of $\mathrm{Abel},{ }^{4}$ and is probably a mixture of $\mathrm{Fe}_{3} \mathrm{C}$ and pure iron. I have diagrammatically indicated its presence in Fig. 4, which will enable me to summarize the work of many experimenters. The diagram (Fig. 4) will serve, for the furpose of illustration:

"Ber. der deutsch. chem. Gesellschaft, vol. xviii. p. 998.

2 Ann. des Mines t iii. I 833 p. 229.

3 The reader must refer to the Journal of the Iron and Steel Inst.tute No. i., 1887,255

4 Proc. Inst. Mech. Engineers, January $188_{3}$ 
to indicate the appearance when soft, hardened, and tempered steel are respectively treated with a solvent which acts gently on the mass.

\section{IRON AND CARBON.}

\section{(0.2 TO I-5 PER CEMT OF CARBON.)}

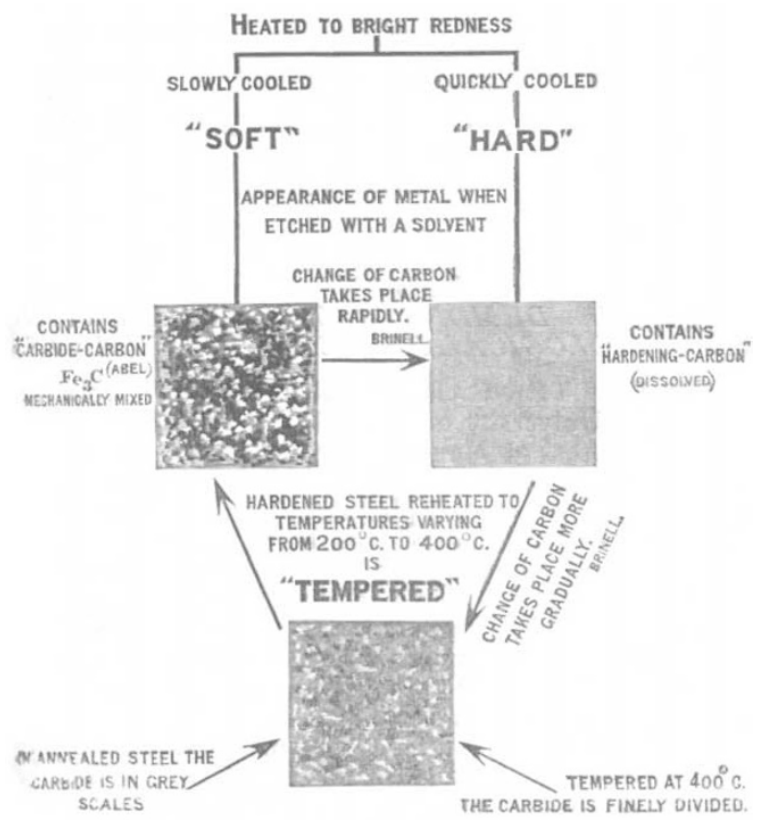

FIG. 4.

A study of the above diagram and of the admirable work of Ledebur ${ }^{1}$ will show how complex the relations of carbon and iron really are, but, for the purposes of the present inquiry it miy fairly be asked, Dues a change in the "mode of existence" of carbon in iron sufficiently explain the main facts of hardening and tempering ? It does not. It is possible to obtain by rapid cosling from a certain temperature steel which is perfectly soft, although analysis proves that the carbon is present in the form which we have recognized as "hardening carbon." No doubt in the hardening of steel the carbon changes its mole of existence, but we must seek som $\approx$ other theory to explain ail the facts, and in order to do this we will turn to the behaviour of the iron itself.

In approaching this portion of the subject a few elementary facts relative to the constitution of matter mist be recalled, and in doing so I must again appeal briefly to history. It is universally accepted that metals, like all elements, are composed of atoms of definite weights and volumes grouped in molecules. In order actually to transmute one metal into another it would be necessary to discover a method of attacking not the molecule but the atom, and of changing it, and this, so far as is known, has not yet been done ; but it is possible, by influences waich often appear to be very slight, to change the relations of the molecules to each other, and to alter the arrangements or distribution of the atoms within the molecules, and by varying in this sense the molecular arrangement of certain elements, they may be made to pass into forms which are very different from those in which we ordinarily know them. Carbon, for instance, when free, or when associated with iron, miy readily be changed from the diamond to the grap'xitic

\footnotetext{
I Stahl und Eisen, vol. viii., r888, p. 742.
}

form, though the converse change has not as yet been effected.

Sulphur, again, with which you are familiar as a hard, brittle, yellow solid, may be prepared and maintained for a little time in the form of this brown viscous mass, but this latter form of sulphur soon passes spontaneously and slowly at the ordinary temperature, and instantaneously at $100^{\circ}$, to the solid octahedral yellow modification with evolution of heat. The viscous form of sulphur is an allotropic modification of that element. A few cases of allotropy in metals have already been established, and when they do occur they give rise to problems of vast industrial importance. Such molecular changes in metals are usually produced by the addition of a small quantity of foreign matter, and I have elsewhere tried to show that the molecular change produced by the action of traces upon masses is a wide-spread principle of nature, and one which was recognized at the dawn of the science of chemistry, even in the seventh century, although distorted explanations were given of well-known fdcts, and gave rise to entirely false hopes. But it is the same story now as in mediæval times: the single grain of powder which Raymond Lully said would transmute millions of its weight of lead into gold-the single grain of stone that Solomon Trismosin thought would secure perpetual youth-had their analogues in the small amount of plumbago which, to Bergman's astonishment in the eighteenth century, converted iron into steel. By his time it was recognized that the right use of alchemy consisted in the application of its methods to industry, and we still wonder at the minuteness of the quantity of certain elements which can profoundly affect the properties of metals. The statements are true, and are not derived from poetical literature, early or late. Even in the moral world the significance of the action of traces upon masses has been recognized, and the method of the alchemist survives in the administration of the small quantity of powder which, in the imagination of Robert Louis Stevenson, will produce the malevolent Hyde modification of the benevolent Dr. Jekyll. In thus borrowing an illustration from one of the most refined and subtle writers of our time, I do not fear the taunt of Francis Bacon," that "sottishly do the chymics appropriate the fancies and delights of poats in the transformation of bodies to the experiments of their furnaces; "for, although it $\mathrm{m} x y$ not be possible to traismute matals, it is easy so to transform them, by very slight influences, that as regards special service required from them they mxy behave either usefuily or entirely prejuticially.

In attempting to illustrate this part of the subject I cannot take the most striking cases, as it is difficult to demonstrate them in the tims at my disposal. The following experimant, which does not, however, depend upon the action of a trace upon a mass, will enable me to lead up to the point I wish to insist upon. It consists in the release of gol 1 from its alloy with potassium. When the alloy is treated with water, the gold comes down in a finely divided, dark brown, chemically active state. [Experiment shown on the screen.]

I have chosen this experiment because it was a similar one that first roused suspicion that pure iron could exist in more than one form.

The question at once suggests itself, Can iron behave in a similar mınner: is an allotropic form of iron known? Joule afforded experimental evidence for an affirmative answer to this question nearly forty years ago by communicating to the British Association in 1850 a paper on some amalgams. The result of his experiments, published in detail later, ${ }^{2}$ in a paper which has been sadly neglected, showed that iron released from its amalgam with mercury is chemically active, as it com-

I Piefare to the "Wiston of the Ancients."

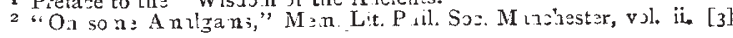
P. II5. 
bines readily with the oxygen of the air at the ordinary temperature, and he claims that the iron so set free is allotropic; but Joule did much more than this. Magnus had shown (185I) that the thermo-electric properties of hard and soft steel and iron differ. Joule, in a paper on some thermo-electric properties of solids, incidentally shows that the generation of a thermo-electric current affords a method of ascertaining the degree of carburization of iron, and he appeals to the "thermo-electricity of iron in different states" as presenting a "fresh illustration of the extraordinary physical changes produced in iron by its conversion into steel," and he adds the expression of the belief "that the excellence of the latter metal might be tested by ascertaining the amount of change in thermo-electric condition which can be produced by the process of hardening." 1 It is by a thermo-electric method that the views as to the existence of iron in allotropic forms has been confirmed. Jullien seems to have inclined to the view that iron is allotropic in his "Théorie de la Trempe," 2 published in 1865 , but he cannot be said to have added much to our knowledge, although he certainly directed attention to the importance of hardening and tempering steel.

The next step was made in Russia, in 1868 . Chernoff, who has found an admirable exponent to English readers in Mr. W. Anderson, President of Section $G$, showed that steel could not be hardened by rapid cooling until it had been heated to a definite temperature - to a degree of redness which he called $a$. Then in 1873 , Prof. Tait used this expression in a Rede Lecture delivered at Cambridge: "It seems as if iron becomes, as it were, a different metal on being raised above a certain temperature ; this may possibly have some connection with the ferricum and ferrosum of the chemists." $\mathrm{He}$ also published his now well-known "first approximation to a thermo-electric diagram," which is of great interest in view of recent work. At about this time those specially interested in this question remembered that Gore ${ }^{4}$ had shown that a curious molecular change could be produced by heating an iron wire, which sustains a momentary elongation on cooling. Barrett repeated Gore's experiment, and discovered that as an iron wire cools down it suddenly glows, a phenomenon to which he gave the name recalescence, and these investigations have been pursued and developed in other directions by many skilful experimenters. ${ }^{5}$ In 1879 , Wrightson ${ }^{6}$ called attention to the abnormal expansion of carburized iron at high temperatures.

The next point of special importance seems to me to be that recorded by Barus, who, by a thermo-electric method, showed, in an elaborate paper published in $1879,^{7}$ that "the hardness of steel does not increase continuously with its temperature at the moment of sudden cooling, but at a point lying in the dark-red heat the glass-hard state" may suddenly be attained by rapid conling. I shall have again to refer to the remarkable series of papers published by Barus and Strouhal, ${ }^{8}$ embodying the results of laborious

s Phil. Trans, cxlix., r859, p. 9r.

2 "Annexe au traité de la Métallurgie du Fer," 1865

3 Nature, viii., 1873 , pp. 86 , 122 ; and Trans. Roy. Soc. Edin., xxvii. 1873 , p. 125.

4 Proc Roy. Soc, xvii., r869, p. 260 .
5 G. Forbes, Proc. Roy. Soc. Edin., viii., I874, 363 ; Norris, Proc. Roy. Soc., xxvi., I877, I27; Tomlinson, Phil. Mag., xxiv., I887, 256; xxv., pp. 4 , 103, and 372 ; xxvi. p. 18 ; Newall, Phil. Mag., xxiv., 1887, 435; xxv, 1888,

p. 5 I0.

Journ. Iron and Steel Inst, , No. ii. 1879 ; No. i. 1880

7 Barus, Phil. Mag., viii., 1879. p. 34 I.

8 "Hardness (Temper), its Electrical and other Characteristics," Barus, Phil. Mag., viii p. 34r, 1879: Wied. Ann. vii. p. $3^{8} 3$, 1879; Strouhal and Barus, Wied. Ann., xi. p. 930, 1880; ibid., xx. p. 525, I883. "Hardness and Magnetization," Wied. Ann., xx. pp. 537, 662, r883. "Density and (Internal) Srructure of Hard Steel and of Quenched Glass," Barus and Strouhal, American Journ., xxxi. p. 386, 1886; ibid., p. 439 ; ibid., xxxi. p. 181, r886. "Temper and Chemical Composition," $\mathrm{Am}$ Journ., xxxii. p. 276, 1886. "Temper and Viscosity," Am. Journ., xxxii. p. $444, \mathrm{r} 886$; ibid., xxxiii. p. 20,1887 ; Barus, ibid., xxxiv. p. $\mathrm{x}, \mathrm{x} 88_{7}$; ibid. xxxiv. p. 175,1887 . These papers, systematically discussed and enlarged, are embodied with new matier in the Bulletins of the United States Geological Survey, viz. :-Bull., No. 14, pp. x-226, 1885; Bull, No. 27. pp. 30-6r, 1886; Bull., No. 35, pp. 11.60, 1836; Bull., No.42, pp. 98-1 31, т887 investigations, to which, in the limited space of this lecture, I can do but scanty justice ; and finally, within the last few years, Pionchon ${ }^{1}$ showed that at a temperature of $700^{\circ}$ the specific heat of iron is altogether exceptional, and Le Chatelier ${ }^{2}$ has detected that at the same temperature a change occurs in the curve representing the electromotive force of iron-both experimenters concluding that they had obtained evidence of the passage of iron into an allotropic state.

Osmond, 3 in France, then made the observations of Gore and Barrett the starting-point of a fresh inquiry, which will now be considered at some length, as Osmond has arrived at conclusions of much interest and importance.

(To be continued.)

ON A NEW APPLICATION OF PHOTOGRAPHY
TO THE DEMONSTRATION OF CERTAIN PHYSIOLOGICAL PROCESSES IN PLANTS.

M R. WALTER GARDINER, Lecturer on Botany in the University of Cambridge, who delivered the evening address at Newcastle on "How Plants maintain themselves in the Struggle for Existence," has discovered a new method of printing photographic negatives, employing living leaves in place of sensitive paper. Mr. Gardiner read a paper on the subject before the British Association. Before dealing with the immediate subject of his paper, the author described how prints may be obtained from Protococci, or the free-swimming swarm-spores of many green Algæ. It is possible to take advantage of their sensitiveness to light. Into one end of a water-tight box, a thin glass plate is securely fitted. The negative to be printed is then placed next the glass, film side nearest. The box is filled with water containing a fairly large quantity of swarm-spores. The lid is shut down, and the whole is exposed to diffused light. In the case of a strong and well-developed negative, the swarm-spores swim towards the most highly-illuminated parts, and there in the greatest numbers come to rest, and settle upon the glass, so that, after some four or six hours, on pouring out the water and removing the negative, a print in green swarm-spores can be obtained. The print may be dried, fixed with albumen, stained, and varnished. The author then dwelt upon the well-known fact that the whole of the animal life upon the globe depends directly or indirectly upon the wonderful synthetic formation of proteid and protoplasm which takes place in the living tissue of plants containing chlorophyll, i.e. green plants, or, to be more exact, in the green chlorophyll corpuscles. $\mathrm{He}$ stated that, whatever is the exact chemical nature of the process, this is at least clear, that the first visible product of the assimilatory activity is starch, which, moreover, is found in the chlorophyll grains. The presence of this starch can be made manifest by treating a decolorized leaf with a water solution of iodine dissolved in potassic iodide. This formation of starch only takes place under the influence of light; the radiant energy of the sun providing the means of executing the profound synthetic chemical change, and building up proteid from the carbonic acid of the air which is taken up by the leaves and the salts and water of the soil absorbed by the roots. If a plant (and preferably a plant with thin leaves) be placed in the dark over-night, and then brought out into the light next morning, the desired leaves being covered with a sharp and well-developed negative, starch is formed

Comptes rendus, cii., r\&86, pp. 675 and 1454 , ciii. p. 1122.

Ibict., cii. p 819.

3 The reader will find the principal part of Osmond's work in the following papers: Osmond et Werth, "Thé rie Cellulaire des Propriétés de l'Acier," Ann. des Mines, viij., I 885 , p. 5 ; "Transformations du Fer et du Carbnne," Paris, Baudoin et Cie., 1888; "'Études Métallurgiques," Ann. des Mines, Juillet-Août, 1888. There is also a very interesting paper, "Sur les Nouveaux Procédés de Trempe," which he communicated to the Mining and Metallurgical Congress, Paris, i 889. 